\title{
Impacts of the regulatory model for market risk capital: application in a special savings company, an insurance company, and a pension fund
}

\author{
Betty Lilian Chan \\ Fundação Escola de Comércio Álvares Penteado, Departamento de Ciências Contábeis, São Paulo, SP, Brazil
}

Felipe Tumenas Marques

BNP Paribas Cardif, São Paulo, SP, Brazil

Received on 05/27/2016 - Desk acceptance on 06/13/2016 - $3^{\text {rd }}$ version approved on 05/30/2017

\section{ABSTRACT}

In line with the regulation brought in by Solvency II, the Superintendence of Private Insurance (Susep) introduced the market risk capital requirement at the end of 2015 , with $50 \%$ of the minimum capital for this type of risk being required by December $31^{\text {st }} 2016$ and $100 \%$ the following year. This regulatory model consists of calculating parametric value at risk with a 99\% confidence level and a three month time horizon, using the net exposure of expected cash flows from assets and liabilities and a covariance matrix updated with market data up to July 2014. One limitation of this regulatory approach is that the updating of the covariance matrix depends on prior approval by the National Council of Private Insurance, which can limit the frequency the covariance matrix is updated and the model's adherence to the current market reality. As this matrix considers the period before the presidential election, the country's loss of investment grade status, and the impeachment process, which all contributed to an increase in market volatility, this paper analyses the impacts of applying the regulatory model, considering the market volatility updated to December $31^{\text {st }} 2015$, for a special savings company (sociedade de capitalização), an insurance company, and an pension fund. Furthermore, the paper discusses the practical implications of the new market risk requirement for managing the investments of the entities supervised by Susep, listing the various assumptions that can be used in the regulated entities' Asset and Liability Management decision models and possible trade-offs to be addressed in this process.

Keywords: regulatory capital, market risk capital, solvency, pension, open pension fund. 


\section{INTRODUCTION}

Different stakeholders can have different views with regards to the optimal capital structure (proportion of own capital and third-party capital) for companies. Shareholders, aiming to maximize return and minimize risk, tend to prefer the minimum allocation of capital, while other stakeholders, such as funders, prefer the maximum capital possible, since in the event of possible misfortunes over the course of business, the possible loss can be mitigated by a company's own capital. Within this setting the following question arises: is the market capable of functioning adequately without the State's interference. This is a big question guiding the discussion between regulation and self-regulation, with the former predicting that government rules should restrict private activity in order to maintain market equilibrium, while the latter argues that the rules should be set by market participants themselves.

Due to the economic, financial, and social relevance of the financial and insurance market, the perspective that has stood out, although regulation and self-regulation are to some extent complementary, is the one that argues that it is the State's job to intervene in the market, by establishing standards, however minimum, to guarantee the stability of the system and correct possible distortions. The more complex the products and services involved, the greater the need for State regulation, in order to uphold commitments made to the most vulnerable (in other words consumers) and maintaining market equilibrium forms part of this.

Along these lines and given the increased complexity of financial services and scandals involving big corporations, the Basel II Accord emerged (and subsequently Basel III), introducing methodologies for calculating minimum levels required of capital that are more sensitive to risk, allowing a lower capital allocation for institutions that use risk management practices better. This tendency for the insurance market in European Union countries has resulted in Solvency II.

Following the global movement, in Brazil new solvency rules for the insurance market have been issued, initially establishing those for capital allocation to cover subscription, credit, and operational risks.

In December 2014, CNSP Resolution n. 317 was issued (Superintendence of Private Insurance [Susep], 2014) and subsequently consolidated by CNSP Resolution n. 321 (Susep, 2015) and altered by CNSP Resolution $\mathrm{n}$. 343 (Susep, 2016). It introduced criteria for calculating risk capital based on market risk for insurers (INSs), pension funds (PFs), special saving companies (SSCs), and local reinsurers. The regulatory model consists of calculating parametric value at risk (VaR), considering $99 \%$ confidence for a three month time horizon. However, the covariance matrix established in the rule for calculating VaR was updated up to July 2014, prior to the presidential election, the country's loss of investment grade status, and the impeachment process, which all contributed to an increase in market volatility. Besides this limitation of this regulatory approach, in order to update the covariance matrix to best reflect the underlying reality, a new resolution needs to be approved by the National Council of Private Insurance (CNSP), limiting the frequency of updates and the adequacy of the covariance matrix to the current market reality. Along these lines, given the increase in market volatility, the following question arises: what is the impact of updating the covariance matrix in the VaR calculation for market risk capital purposes?

This article therefore seeks to analyze the results of applying the approach defined by CNSP Resolution n.321 (Susep, 2015), incorporating market volatility up to December $31^{\text {st }} 2015$, for market risk capital for an SSC, an INS, and an PF. Moreover, the paper will discuss the practical implications of the new market risk requirement for managing the investments of entities supervised by the Superintendence of Private Insurance (Susep).

The article is divided into five sections, including this introduction. The second section presents the literature review, the third presents the methodology used, and the fourth constitutes an analysis of the need to adjust regulatory capital for the case presented. Finally, the fifth section presents the conclusions. 


\subsection{Capital Requirement}

Since the 1980s, financial institution and insurance company operations have evolved considerably, particularly with the regulations introduced by the Basel and Solvency accords. The regulations are structured based on the same three pillars:

- Pillar I - Quantitative Requirements: calculation of solvency capital requirements and minimum capital required based on a standard or an internal model.

- Pillar II - Supervisor review: general principles that govern the regulation of risk management and internal controls and process reviews.

- Pillar III - Market discipline: guidelines regarding the transparency and reporting of information related to solvency and financial situation.

These pillars seek to incentivize better practices for managing the risks to which INSs, reinsurers, SSCs, and PFs are exposed and can be found both in the recommendations from the International Association of Insurance Supervisors (IAIS, 2005) and in Solvency II of the European Union (Directive of the European Parliament and of the Council [EC], 2009) and in the Basel II accord (Basel Committee on Banking Supervision [BCBS], 2004) for banks.

In Brazil, Susep and CNSP have worked on developing the regulatory and supervisory framework based on the three pillars instituted in Solvency II.

In Pillar I, the regulation for additional capital for risk of insurer and reinsurer damage claims was introduced by CNSP resolutions n. 158 (Susep, 2006) and n. 188 (Susep, 2008), respectively. The criteria for establishing the capital for credit risk originated with CNSP Resolution n. 228 (Susep, 2010) and the capital for operational risk was regulated by CNSP Resolution n. 283 (Susep, 2013).

In 2013, in continuity of the polic•y for implanting supervision based on risk, Susep established a technical group to present the criteria and methodologies for measuring the regulatory risk capital requirement related to the market risk of supervised companies.

According to the presentation from the Susep technical group, carried out on April $26^{\text {th }} 2013$, the market under supervision accounted for $\mathrm{R} \$ 549$ billion in assets, with $\mathrm{R} \$$ 462 billion in financial assets distributed in the following way:
- $\mathrm{R} \$ 424$ billion for the insurance segment;

- $\mathrm{R} \$ 1$ billion for the PF segment;

- $\mathrm{R} \$ 29$ billion for the special savings company segment;

- $\mathrm{R} \$ 8$ billion for the local reinsurer segment.

The relevance of the numbers highlights the economic and social importance of these segments in Brazil and explains the regulatory body's concern with defining the basic metrics to be observed in order to maintain the solvency of the sector.

According to CNSP Resolution n. 317 (Susep, 2014), consolidated by CNSP Resolution n. 321 (Susep, 2015), INSs, PFs, SSCs, and local reinsurers will have to completely adjust to the new capital regulation for market risk by 2017, with the following capital requirement chronogram being established:

a. $0 \%$ of the capital for market risk by December $30^{\text {th }} 2016$;

b. $50 \%$ of the capital for market risk between December $31^{\text {st }} 2016$ and December $30^{\text {th }} 2017$; and

c. $100 \%$ of the capital for market risk by December $31^{\text {st }} 2017$

This shows that the subject of this study is contemporary and extremely relevant for the companies supervised by Susep.

Moreover, given the relevance of this regulation, CNSP Resolution n. 343 (Susep, 2016) altered the way of calculating adjusted net equity (ANE) to make it more sensitive to variations in the market value of assets and liabilities and suited to the introduction of the capital portion for market risk.

\subsection{Asset and Liability Management}

The use of the concept of market risk based on the net exposure between assets and their respective liabilities serves as a factor that incentivizes the use of asset and liability management (ALM) practices by the entities under Susep supervision.

The basic aim of an entity is to retain enough reserves to honor commitments to its participants or clients, however the uncertainty component with regards to what the assets and liability values will be, and consequently the mismatch between these, make the task of managing this process a challenge. Within this setting, ALM is a 
key process for risk management, enabling decisions to be taken that are consistent with the behavior of an organization's assets and liabilities, and making it possible to monitor and control management variables, such as liquidity, solvency, and return, among others. With the new market risk capital requirement issued by Susep, this variable is added to the scope of the ALM process in the supervised entities.

The ALM models can be divided into two main categories: deterministic models and stochastic models. The first group includes the cash flow matching models, which seek a set of assets with a cash flow equal to that of the liabilities, and dedication, which seek assets with the closest cash flow possible to that of the liabilities (due to the difficulty of finding assets that make cash flow matching possible).

The dedication models gave rise to the immunization models (Ryan, 2014), whose core idea is to find an asset portfolio, at the lowest price possible, whose cash flow is greater or equal to that of liabilities.

The measures used for this purpose are normally dollar-duration and convexity; however these measures assume parallel shifts in interest rates, which is difficult to find in practice. More advanced measures, such as key rate duration vectors, have been proposed in the literature (Nawalkha, Soto, \& Zhang, 2003); however a recent study (Carcano \& Dall'O, 2011) found evidence that the use of more sophisticated models leads to a higher exposure to model errors, reducing the quality of the hedge created by these approaches.

In the second category, that of stochastic models, optimization models are used, considering the possible variations in cash flows and asset and liability values, which take on a stochastic behavior. The scope of this category ranges from the models that consider dynamic programming (Cairns, Blake, \& Dowd, 2006) to models based on risk quantiles, such as VaR (Blake, Cairns, \& Dowd, 2001).

\subsection{Market Risk}

Market risk has developed considerably since 1994, with JP Morgan bank publishing the RiskMetrics methodology (Morgan, 1996), in which the VaR metric came to be the reference for calculating market risk both in the academic field and in the financial market.

$\mathrm{VaR}$ is defined as the highest loss expected for a time horizon and a particular confidence interval. VaR can be calculated in different ways, according to the three methodologies first presented by Risk Metrics: Parametric (which assumes that financial returns have a known distribution), Historical Simulation (in which the quantile established by the VaR is sought in the historical distribution of the portfolio returns that are being analyzed), and Monte Carlo Simulation (which seeks to simulate the behavior of market prices).

Like the Brazilian Central Bank (BCB), which uses VaR as a metric for the market risk capital requirement for its regulated entities, in the insurance market Susep adopted $\mathrm{VaR}$ as a metric for calculating the capital requirement for market risk.

As established by CNSP Resolution n. 317 (Susep, 2014), the required capital for market risk will be the parametric VaR for three months, with $99 \%$ confidence.

The covariance matrix for calculating the parametric $\mathrm{VaR}$ is estimated using the exponentially weighted moving average (EWMA), based on the parameters of the term structure of interest rates (TSIR) published monthly by the authority itself, and used for the liability adequacy test (LAT) calculation, as well as the Bovespa Index, dollar, and Brazil Commodities Index (BCI) series of returns. The covariance matrix adopted in the current resolution refers to July 2014.

\section{INTEREST PROBLEM AND METHODOLOGY}

This paper aims to analyze the impacts of the new market risk capital requirement by evaluating the results for an SSC, an INS, and an PF, for December 2015.

As well as the direct impact of the capital requirement on these companies, the possible reflection on the need for market risk capital will also be analyzed, where data up to December 2015 update the covariance matrix used in calculating VaR, given that the current matrix uses data up to July 2014.

The covariance matrix will be updated in accordance with the methodology established by Susep, which consists of applying the EWMA method for the most recent data. The updating method is based on the standard EWMA formula, 


$$
\sigma_{t}^{2}=\lambda \sigma_{t-1}^{2}+(1-\lambda) r_{t-1}^{2}
$$

in which $\sigma$ is the variance, $\lambda$ is the decay factor used to analyzed. For each item in the matrix, the covariance is update the information, and $r$ is the return of the series estimated using the following correlation formula:

$$
\rho_{a, b}=\frac{\operatorname{Cov}\left(r_{a}, r_{b}\right)}{\sigma_{a} \sigma_{b}}
$$

converted into:

$$
\operatorname{Cov}(a, b)_{t}=\rho \sigma_{a, t} \sigma_{b, t}
$$

in which the estimates for volatility $\sigma$ will be those obtained by the EWMA and the correlation $\rho$ used will be the historical correlation of the series, considering the same period used by Susep to estimate the decay factors.
The decay factors used will be the same published by Susep in the Market Risk Report - Calculation of Factors GT. The factors are presented in Table 1:

Table 1 Decay factors

\begin{tabular}{lll}
\hline Series of returns & Decay factor & 0.92 \\
\hline Fixed rate & 0.85 \\
\hline IGP-M linked rate & 0.94 \\
\hline IPCA linked rate & 0.92 \\
\hline RR linked rate & 0.73 \\
\hline Foreign exchange linked rate & 0.97 \\
\hline IGP-M & 0.96 \\
\hline IPCA & 0.97 \\
\hline RR & 0.96 \\
\hline Bovespa Index & 0.96 \\
\hline ICB & 0.98 \\
\hline
\end{tabular}

IGP-M: Brazilian General Market Price Index; IPCA: Brazilian Consumer Price Index; RR: reference rate.

Source: Elaborated by the authors.

It also bears mentioning that the methodology established in the calculation of the net exposures between assets and liabilities, which are mapped by maturity and risk factor in the VaR calculation, does not consider new business, but merely the risk already assumed until then by the supervised entities (it presupposes run-off companies).

Besides VaR, the analyses will also use marginal VaR, which measures how much the VaR would change for a monetary unit change in each exposure, and component
VaR, which measures how much each exposure contributes to total VaR (Alexander, 2009; Gourieroux, Laurent, \& Scaillet, 2000).

Despite the better alternative for reducing the VaR defined by the model, and consequently, the required capital being the decrease in the net exposure in the risk factors via ALM tools, these metrics serve as a parameter for evaluating the contributions from each factor to the total VaR. 


\section{RESULTS}

The first stage in the analysis consists of allocating the financial flows of the assets and liabilities into the risk factors, or fixed maturities, in the net exposure calculation for each factor.
The net exposure data for the three companies are presented in Table 2 and are divided by the respective total financial assets, in order not to leave the numbers of the three companies apparent.

Table 2 Net exposures by risk factor

\begin{tabular}{|c|c|c|c|c|}
\hline Maturity & Risk factor & SSC (\%) & INS (\%) & PF $(\%)$ \\
\hline 1 & Dollar & 0.000 & 0.000 & 0.000 \\
\hline 21 & Foreign exchange linked rate & 0.000 & 0.000 & 0.000 \\
\hline 63 & Foreign exchange linked rate & 0.000 & 0.000 & 0.000 \\
\hline 126 & Foreign exchange linked rate & 0.000 & 0.000 & 0.000 \\
\hline 252 & Foreign exchange linked rate & 0.000 & 0.000 & 0.000 \\
\hline 378 & Foreign exchange linked rate & 0.000 & 0.000 & 0.000 \\
\hline 504 & Foreign exchange linked rate & 0.000 & 0.000 & 0.000 \\
\hline 630 & Foreign exchange linked rate & 0.000 & 0.000 & 0.000 \\
\hline 756 & Foreign exchange linked rate & 0.000 & 0.000 & 0.000 \\
\hline 1008 & Foreign exchange linked rate & 0.000 & 0.000 & 0.000 \\
\hline 1260 & Foreign exchange linked rate & 0.000 & 0.000 & 0.000 \\
\hline 2520 & Foreign exchange linked rate & 0.000 & 0.000 & 0.000 \\
\hline 1 & IGP-M & 0.000 & 4.220 & -7.266 \\
\hline 63 & IGP-M linked rate & 0.000 & 0.409 & -0.830 \\
\hline 126 & IGP-M linked rate & 0.000 & 0.473 & -0.997 \\
\hline 252 & IGP-M linked rate & 0.000 & 0.567 & -1.242 \\
\hline 378 & IGP-M linked rate & 0.000 & 0.505 & -1.340 \\
\hline 504 & IGP-M linked rate & 0.000 & 0.616 & -0.479 \\
\hline 630 & IGP-M linked rate & 0.000 & 0.515 & -0.269 \\
\hline 756 & IGP-M linked rate & 0.000 & 0.451 & 0.316 \\
\hline 1008 & IGP-M linked rate & 0.000 & 0.352 & 1.132 \\
\hline 1260 & IGP-M linked rate & 0.000 & 0.734 & 3.067 \\
\hline 2520 & IGP-M linked rate & 0.000 & -0.048 & 3.440 \\
\hline 3780 & IGP-M linked rate & 0.000 & 0.610 & 2.819 \\
\hline 5040 & IGP-M linked rate & 0.000 & -0.405 & 1.775 \\
\hline 6300 & IGP-M linked rate & 0.000 & -0.321 & -0.008 \\
\hline 7560 & IGP-M linked rate & 0.000 & -0.161 & -0.033 \\
\hline 8820 & IGP-M linked rate & 0.000 & -0.076 & -0.030 \\
\hline 10080 & IGP-M linked rate & 0.000 & -0.036 & -0.022 \\
\hline 11340 & IGP-M linked rate & 0.000 & -0.016 & -0.014 \\
\hline 12600 & IGP-M linked rate & 0.000 & -0.011 & -0.020 \\
\hline 1 & IPCA & 44.614 & 8.075 & -5.997 \\
\hline 63 & IPCA linked rate & 1.876 & 0.813 & 0.068 \\
\hline 126 & IPCA linked rate & 1.008 & 1.327 & 0.090 \\
\hline 252 & IPCA linked rate & 2.339 & 1.610 & 0.134 \\
\hline 378 & IPCA linked rate & 4.264 & 1.492 & 0.125 \\
\hline 504 & IPCA linked rate & 2.380 & 1.038 & 0.147 \\
\hline 630 & IPCA linked rate & 1.445 & 0.834 & 0.168 \\
\hline 756 & IPCA linked rate & 3.315 & 1.076 & 0.220 \\
\hline 1008 & IPCA linked rate & 4.075 & 0.945 & 0.290 \\
\hline 1260 & IPCA linked rate & 7.756 & 0.681 & 0.699 \\
\hline 2520 & IPCA linked rate & 6.874 & -0.665 & 0.902 \\
\hline 3780 & IPCA linked rate & 2.531 & -0.884 & 0.701 \\
\hline 5040 & IPCA linked rate & 1.926 & -0.484 & 0.609 \\
\hline 6300 & IPCA linked rate & 1.120 & -0.204 & 0.470 \\
\hline 7560 & IPCA linked rate & 1.432 & -0.017 & 0.770 \\
\hline 8820 & IPCA linked rate & 0.561 & 0.194 & 0.529 \\
\hline 10080 & IPCA linked rate & 0.076 & -0.004 & 0.076 \\
\hline
\end{tabular}


Table 2 Cont.

\begin{tabular}{|c|c|c|c|c|}
\hline Maturity & Risk factor & SSC (\%) & INS (\%) & PF (\%) \\
\hline 11340 & IPCA linked rate & 0.000 & -0.007 & 0.000 \\
\hline 12600 & IPCA linked rate & 0.000 & -0.006 & 0.000 \\
\hline 1 & $\mathrm{RR}$ & -53.272 & -0.457 & 1.767 \\
\hline 63 & RR Linked rate & 4.701 & -0.009 & -0.342 \\
\hline 126 & RR Linked rate & 3.782 & -0.018 & -0.419 \\
\hline 252 & RR Linked rate & -0.369 & -0.021 & -0.426 \\
\hline 378 & RR Linked rate & -9.193 & -0.026 & -0.261 \\
\hline 504 & RR Linked rate & -8.713 & -0.023 & -0.107 \\
\hline 630 & RR Linked rate & -7.256 & -0.018 & -0.049 \\
\hline 756 & RR Linked rate & -9.852 & -0.024 & -0.032 \\
\hline 1008 & RR Linked rate & -11.622 & -0.036 & -0.021 \\
\hline 1260 & RR Linked rate & -14.333 & -0.091 & -0.025 \\
\hline 2520 & RR Linked rate & -2.473 & -0.093 & -0.037 \\
\hline 3780 & RR Linked rate & -0.005 & -0.049 & -0.023 \\
\hline 5040 & RR Linked rate & 0.000 & -0.024 & -0.013 \\
\hline 6300 & RR Linked rate & 0.000 & -0.011 & -0.007 \\
\hline 7560 & RR Linked rate & 0.000 & -0.005 & -0.004 \\
\hline 8820 & RR Linked rate & 0.000 & -0.002 & -0.002 \\
\hline 10080 & RR Linked rate & 0.000 & -0.001 & -0.001 \\
\hline 11340 & RR Linked rate & 0.000 & 0.000 & 0.000 \\
\hline 12600 & RR Linked rate & 0.000 & 0.000 & 0.000 \\
\hline 21 & Fixed rate & 0.525 & -1.052 & -0.007 \\
\hline 63 & Fixed rate & 0.354 & -1.070 & 0.000 \\
\hline 126 & Fixed rate & 0.347 & -0.634 & 0.007 \\
\hline 252 & Fixed rate & 0.453 & -0.249 & 0.174 \\
\hline 378 & Fixed rate & 4.026 & 0.199 & 0.009 \\
\hline 504 & Fixed rate & 3.527 & 0.025 & 0.098 \\
\hline 630 & Fixed rate & 0.327 & -0.139 & 0.008 \\
\hline 756 & Fixed rate & 0.525 & 0.029 & 0.222 \\
\hline 1008 & Fixed rate & -0.026 & -0.032 & 0.039 \\
\hline 1260 & Fixed rate & 0.900 & 0.066 & 0.040 \\
\hline 2520 & Fixed rate & 0.150 & 0.009 & 0.064 \\
\hline 3780 & Fixed rate & 0.000 & 0.000 & 0.000 \\
\hline 1 & Stock & 0.268 & 0.164 & 0.000 \\
\hline 1 & Commodities & 0.000 & 0.000 & 0.000 \\
\hline
\end{tabular}

SSC: special savings company; PF: pension fund; INS: insurer; IGP-M: Brazilian General Market Price Index; IPCA: Brazilian Consumer Price Index; RR: reference rate.

Source: Elaborated by the authors.

For the SSC, apparently the company's strategy is to manage the risk of exposure of liabilities indexed to the reference rate (RR) by allocating into assets indexed to the Brazilian Consumer Price Index (IPCA).

As for the INS, there is no clear standard, given that the positive net exposures are distributed into various categories of risk factors, as well as the negative net exposures.

With regards to the PF, it appears that in order to address the residual liabilities indexed to the RR and to the Brazilian General Market Price Index (IGP-M), the company allocates into assets indexed to the fixed rate and IPCA rates. It bears mentioning that Table 2 presents the net exposure of each one of the analyzed companies; that is, if the allocation into assets in a particular risk factor is greater than the exposure of obligations, it is not possible to identify that the company has liabilities exposed to that risk factor.

The next step was to calculate the capital requirement for the three companies, using the published methodology. The capital requirement results, measured in percentage of total financial assets, are presented in Table 3. 
Table 3 Capital requirement for market risk

\begin{tabular}{cccc}
\hline & SSC (\%) & INS (\%) & PF (\%) \\
\hline VaR & 3.25 & 0.39 & 2.18 \\
\hline
\end{tabular}

SSC: special savings company; PF: pension fund; INS: insurer; VaR: value at risk.

Source: Elaborated by the authors.

The VaR is only the starting point for a market risk management model, from which it is possible to evaluate the possible impacts on the current position of an entity's investments. Using marginal VaR and component VaR, the results for the three companies analyzed are in Table 4.

Table 4 Marginal and component value at risk (VaR)

\begin{tabular}{|c|c|c|c|c|c|c|c|}
\hline & & SSC & & INS & & PF & \\
\hline Maturity & Risk factor & Marginal & Component (\%) & Marginal & Component (\%) & Marginal & Component (\%) \\
\hline 1 & Dollar & 0.000 & 0.00 & 0.005 & 0.00 & 0.000 & 0.00 \\
\hline 21 & Foreign exchange linked rate & 0.000 & 0.00 & 0.000 & 0.00 & 0.000 & 0.00 \\
\hline 63 & Foreign exchange linked rate & 0.000 & 0.00 & 0.000 & 0.00 & 0.000 & 0.00 \\
\hline 126 & Foreign exchange linked rate & 0.000 & 0.00 & 0.000 & 0.00 & 0.000 & 0.00 \\
\hline 252 & Foreign exchange linked rate & 0.000 & 0.00 & 0.000 & 0.00 & 0.001 & 0.00 \\
\hline 378 & Foreign exchange linked rate & 0.000 & 0.00 & 0.000 & 0.00 & 0.001 & 0.00 \\
\hline 504 & Foreign exchange linked rate & 0.001 & 0.00 & 0.000 & 0.00 & 0.002 & 0.00 \\
\hline 630 & Foreign exchange linked rate & 0.001 & 0.00 & 0.000 & 0.00 & 0.003 & 0.00 \\
\hline 756 & Foreign exchange linked rate & 0.002 & 0.00 & $(0.000)$ & 0.00 & 0.004 & 0.00 \\
\hline 1008 & Foreign exchange linked rate & 0.003 & 0.00 & $(0.001)$ & 0.00 & 0.006 & 0.00 \\
\hline 1260 & Foreign exchange linked rate & 0.005 & 0.00 & $(0.002)$ & 0.00 & 0.004 & 0.00 \\
\hline 2520 & Foreign exchange linked rate & 0.008 & 0.00 & 0.000 & 0.00 & $(0.003)$ & 0.12 \\
\hline 1 & IGP-M & 0.079 & 0.00 & $(0.028)$ & -26.24 & 0.126 & -42.16 \\
\hline 63 & IGP-M Linked rate & $(0.002)$ & 0.00 & 0.012 & 1.10 & $(0.001)$ & 0.05 \\
\hline 126 & IGP-M Linked rate & $(0.002)$ & 0.00 & 0.016 & 1.68 & 0.008 & -0.45 \\
\hline 252 & IGP-M Linked rate & 0.002 & 0.00 & 0.017 & 2.12 & 0.019 & -1.18 \\
\hline 378 & IGP-M Linked rate & 0.010 & 0.00 & 0.014 & 1.54 & 0.030 & -0.66 \\
\hline 504 & IGP-M Linked rate & 0.017 & 0.00 & 0.010 & 1.38 & 0.039 & -0.48 \\
\hline 630 & IGP-M Linked rate & 0.023 & 0.00 & 0.007 & 0.82 & 0.047 & 0.68 \\
\hline 756 & IGP-M Linked rate & 0.028 & 0.00 & 0.005 & 0.51 & 0.060 & 3.11 \\
\hline 1008 & IGP-M Linked rate & 0.036 & 0.00 & 0.002 & 0.15 & 0.072 & 10.21 \\
\hline 1260 & IGP-M Linked rate & 0.043 & 0.00 & $(0.001)$ & -0.20 & 0.154 & 24.34 \\
\hline 2520 & IGP-M Linked rate & 0.087 & 0.00 & $(0.032)$ & 0.33 & 0.231 & 29.99 \\
\hline 3780 & IGP-M Linked rate & 0.130 & 0.00 & $(0.072)$ & -9.57 & 0.301 & 24.53 \\
\hline 5040 & IGP-M Linked rate & 0.171 & 0.00 & $(0.109)$ & 9.67 & 0.365 & -0.13 \\
\hline 6300 & IGP-M Linked rate & 0.209 & 0.00 & $(0.143)$ & 10.06 & 0.426 & -0.64 \\
\hline 7560 & IGP-M Linked rate & 0.245 & 0.00 & $(0.176)$ & 6.22 & 0.485 & -0.67 \\
\hline 8820 & IGP-M Linked rate & 0.281 & 0.00 & $(0.207)$ & 3.43 & 0.543 & -0.55 \\
\hline 10080 & IGP-M Linked rate & 0.316 & 0.00 & $(0.238)$ & 1.86 & 0.601 & -0.39 \\
\hline 11340 & IGP-M Linked rate & 0.351 & 0.00 & $(0.268)$ & 0.96 & 0.659 & -0.61 \\
\hline 12600 & IGP-M Linked rate & 0.386 & 0.00 & $(0.298)$ & 0.72 & 0.003 & 0.01 \\
\hline 1 & IPCA & 0.006 & 8.05 & 0.033 & 58.99 & 0.004 & -1.16 \\
\hline 63 & IPCA Linked rate & 0.004 & 0.24 & 0.004 & 0.70 & 0.002 & 0.01 \\
\hline 126 & IPCA Linked rate & 0.002 & 0.07 & 0.004 & 1.15 & 0.010 & 0.06 \\
\hline 252 & IPCA Linked rate & 0.008 & 0.55 & 0.006 & 1.97 & 0.022 & 0.13 \\
\hline 378 & IPCA Linked rate & 0.017 & 2.19 & 0.005 & 1.51 & 0.034 & 0.23 \\
\hline 504 & IPCA Linked rate & 0.025 & 1.85 & 0.002 & 0.44 & 0.043 & 0.33 \\
\hline 630 & IPCA Linked rate & 0.032 & 1.43 & $(0.001)$ & -0.20 & 0.053 & 0.53 \\
\hline 756 & IPCA Linked rate & 0.040 & 4.03 & $(0.004)$ & -0.97 & 0.069 & 0.92 \\
\hline 1008 & IPCA Linked rate & 0.052 & 6.49 & $(0.010)$ & -2.01 & 0.081 & 2.62 \\
\hline 1260 & IPCA Linked rate & 0.062 & 14.79 & $(0.015)$ & -2.22 & 0.140 & 5.81 \\
\hline 2520 & IPCA Linked rate & 0.109 & 23.09 & $(0.045)$ & 6.51 & 0.193 & 6.21 \\
\hline 3780 & IPCA Linked rate & 0.154 & 12.00 & $(0.076)$ & 14.81 & 0.246 & 6.90 \\
\hline
\end{tabular}


Table 4 Cont.

\begin{tabular}{|c|c|c|c|c|c|c|c|}
\hline & & SSC & & INS & & PF & \\
\hline Maturity & Risk factor & Marginal & Component (\%) & Marginal & Component (\%) & Marginal & Component (\%) \\
\hline 5040 & IPCA Linked rate & 0.205 & 12.12 & $(0.104)$ & 11.00 & 0.297 & 6.41 \\
\hline 6300 & IPCA Linked rate & 0.256 & 8.81 & $(0.122)$ & 5.46 & 0.370 & 13.10 \\
\hline 7560 & IPCA Linked rate & 0.326 & 14.35 & $(0.143)$ & 0.52 & 0.432 & 10.51 \\
\hline 8820 & IPCA Linked rate & 0.385 & 6.64 & $(0.155)$ & -6.58 & 0.479 & 1.67 \\
\hline 10080 & IPCA Linked rate & 0.426 & 0.99 & $(0.160)$ & 0.15 & 0.522 & 0.00 \\
\hline 11340 & IPCA Linked rate & 0.460 & 0.00 & $(0.165)$ & 0.25 & 0.563 & 0.00 \\
\hline 12600 & IPCA Linked rate & 0.488 & 0.00 & $(0.170)$ & 0.23 & 0.001 & -0.02 \\
\hline 1 & $\mathrm{RR}$ & 0.000 & -0.09 & $(0.000)$ & 0.02 & 0.000 & 0.02 \\
\hline 63 & RR Linked rate & 0.000 & 0.07 & 0.000 & 0.00 & 0.003 & -0.06 \\
\hline 126 & RR Linked rate & 0.001 & 0.14 & 0.000 & 0.00 & 0.007 & -0.13 \\
\hline 252 & RR Linked rate & 0.003 & -0.03 & $(0.000)$ & 0.00 & 0.010 & -0.12 \\
\hline 378 & RR Linked rate & 0.005 & -1.36 & $(0.001)$ & 0.01 & 0.014 & -0.07 \\
\hline 504 & RR Linked rate & 0.007 & -1.77 & $(0.002)$ & 0.01 & 0.018 & -0.04 \\
\hline 630 & RR Linked rate & 0.009 & -1.94 & $(0.004)$ & 0.02 & 0.022 & -0.03 \\
\hline 756 & RR Linked rate & 0.011 & -3.28 & $(0.005)$ & 0.03 & 0.030 & -0.03 \\
\hline 1008 & RR Linked rate & 0.015 & -5.40 & $(0.009)$ & 0.07 & 0.037 & -0.04 \\
\hline 1260 & RR Linked rate & 0.018 & -8.13 & $(0.011)$ & 0.23 & 0.078 & -0.13 \\
\hline 2520 & RR Linked rate & 0.040 & -3.07 & $(0.027)$ & 0.55 & 0.116 & -0.12 \\
\hline 3780 & RR Linked rate & 0.061 & -0.01 & $(0.040)$ & 0.44 & 0.153 & -0.09 \\
\hline 5040 & RR Linked rate & 0.081 & 0.00 & $(0.053)$ & 0.28 & 0.190 & -0.06 \\
\hline 6300 & RR Linked rate & 0.101 & 0.00 & $(0.065)$ & 0.16 & 0.226 & -0.04 \\
\hline 7560 & RR Linked rate & 0.120 & 0.00 & $(0.077)$ & 0.09 & 0.262 & -0.02 \\
\hline 8820 & RR Linked rate & 0.140 & 0.00 & $(0.089)$ & 0.04 & 0.299 & -0.01 \\
\hline 10080 & RR Linked rate & 0.159 & 0.00 & $(0.101)$ & 0.02 & 0.335 & 0.00 \\
\hline 11340 & RR Linked rate & 0.179 & 0.00 & $(0.113)$ & 0.01 & 0.371 & 0.00 \\
\hline 12600 & RR Linked rate & 0.198 & 0.00 & $(0.125)$ & 0.00 & $(0.006)$ & 0.00 \\
\hline 21 & Fixed rate & 0.000 & 0.00 & $(0.000)$ & 0.00 & 0.000 & 0.00 \\
\hline 63 & Fixed rate & 0.001 & 0.01 & 0.000 & 0.00 & 0.002 & 0.00 \\
\hline 126 & Fixed rate & 0.003 & 0.03 & $(0.000)$ & 0.01 & 0.004 & 0.00 \\
\hline 252 & Fixed rate & 0.008 & 0.11 & $(0.001)$ & 0.07 & 0.013 & 0.11 \\
\hline 378 & Fixed rate & 0.015 & 1.84 & $(0.004)$ & -0.19 & 0.023 & 0.01 \\
\hline 504 & Fixed rate & 0.022 & 2.35 & $(0.008)$ & -0.04 & 0.034 & 0.15 \\
\hline 630 & Fixed rate & 0.028 & 0.29 & $(0.012)$ & 0.37 & 0.044 & 0.02 \\
\hline 756 & Fixed rate & 0.035 & 0.57 & $(0.017)$ & -0.10 & 0.054 & 0.55 \\
\hline 1008 & Fixed rate & 0.047 & -0.04 & $(0.024)$ & 0.17 & 0.073 & 0.13 \\
\hline 1260 & Fixed rate & 0.057 & 1.59 & $(0.031)$ & -0.45 & 0.090 & 0.17 \\
\hline 2520 & Fixed rate & 0.099 & 0.46 & $(0.063)$ & -0.13 & 0.157 & 0.46 \\
\hline 3780 & Fixed rate & 0.131 & 0.00 & $(0.093)$ & 0.00 & 0.210 & 0.00 \\
\hline 1 & Stock & 0.001 & 0.01 & 0.002 & 0.06 & $(0.001)$ & 0.00 \\
\hline 1 & Commodities & $(0.059)$ & 0.00 & 0.019 & 0.00 & $(0.068)$ & 0.00 \\
\hline
\end{tabular}

SSC: special savings company; PF: pension fund; INS: insurer; IGP-M: Brazilian General Market Price Index; IPCA: Brazilian Consumer Price Index; RR: reference rate.

Source: Elaborated by the authors.

For the SSC, the maturities linked to the IPCA, despite not being the ones with the highest marginal VaR, are the ones that contributed most to the entity's total VaR. In the case of the INS, the maturity with the greatest weight in the total VaR is that of the IPCA rate, while for the pension fund it is the maturities linked to the IGP-M.

These results were obtained considering the covariance matrix with a July 2014 base date, adopted in CNSP Resolution n. 321 (Susep, 2015); however, the market changes over time, presenting periods of higher and lower volatility for the various risk factors considered. In order to maintain adherence to the market reality, the information in the covariance matrix should be updated, reflecting the supervised entities' real solvency risk.

Thus, this paper sought to estimate the impact of a possible updating of the covariance matrix with the data up to December 2015, considering the TSIR curves available from the Susep website (Susep, 2015), and contemplating the volatility in the economic scenario occurring during the electoral period of 2014 and Brazil's loss of investment 
grade status. This updating tends to better reflect the current scenario, and consequently, better estimate the market risk incurred by the market participants.

With the updating of the covariance matrix, an increase is observed for the market risk capital of the three companies, due to the increase in volatility for the period, with the impact being more accentuated in the SSC, whose need for capital doubles. The results are presented in Table 5.

Table 5 Required capital with updating of the assumptions

\begin{tabular}{ccccc}
\hline & SSC (\%) & INS (\%) & PF (\%) & \\
\hline VaR & 6.37 & 0.43 & 2.34 \\
\hline
\end{tabular}

SSC: special savings company; PF: pension fund; INS: insurer; VaR: value at risk.

Source: Elaborated by the authors.

The SSC has an expressive increase in required capital with the change in the covariance matrix used. The increase in capital is presented in Table 6.

Table 6 Increase in required capital with update

\begin{tabular}{ccccc}
\hline & SSC (\%) & INS (\%) & PF (\%) & \\
\hline VaR & 95.70 & 9.67 & 7.81 & \\
\hline
\end{tabular}

SSC: special savings company; PF: pension fund; INS: insurer; VaR: value at risk.

Source: Elaborated by the authors.

The marginal VaR and the component VaR for the three companies are presented in Table 7.

Table 7 Marginal and component value at risk (VaR) with new matrix

\begin{tabular}{|c|c|c|c|c|c|c|c|}
\hline & & SSC & & INS & & PF & \\
\hline Maturity & Risk factor & Marginal & Component (\%) & Marginal & Component (\%) & Marginal & Component $(\%)$ \\
\hline 1 & Dollar & 0.007 & 0.00 & 0.064 & 0.00 & $(0.078)$ & 0.00 \\
\hline 21 & Foreign exchange linked rate & $(0.000)$ & 0.00 & $(0.000)$ & 0.00 & $(0.000)$ & 0.00 \\
\hline 63 & Foreign exchange linked rate & 0.000 & 0.00 & $(0.000)$ & 0.00 & 0.000 & 0.00 \\
\hline 126 & Foreign exchange linked rate & 0.002 & 0.00 & $(0.003)$ & 0.00 & 0.003 & 0.00 \\
\hline 252 & Foreign exchange linked rate & 0.001 & 0.00 & $(0.005)$ & 0.00 & 0.007 & 0.00 \\
\hline 378 & Foreign exchange linked rate & 0.000 & 0.00 & $(0.005)$ & 0.00 & 0.009 & 0.00 \\
\hline 504 & Foreign exchange linked rate & $(0.001)$ & 0.00 & $(0.007)$ & 0.00 & 0.011 & 0.00 \\
\hline 630 & Foreign exchange linked rate & $(0.001)$ & 0.00 & $(0.009)$ & 0.00 & 0.013 & 0.00 \\
\hline 756 & Foreign exchange linked rate & $(0.001)$ & 0.00 & $(0.011)$ & 0.00 & 0.014 & 0.00 \\
\hline 1008 & Foreign exchange linked rate & $(0.001)$ & 0.00 & $(0.015)$ & 0.00 & 0.018 & 0.00 \\
\hline 1260 & Foreign exchange linked rate & $(0.001)$ & 0.00 & $(0.018)$ & 0.00 & 0.020 & 0.00 \\
\hline 2520 & Foreign exchange linked rate & $(0.002)$ & 0.00 & $(0.005)$ & 0.00 & 0.015 & 0.00 \\
\hline 1 & IGP-M & 0.003 & 0.00 & 0.001 & 0.91 & 0.002 & -0.66 \\
\hline 63 & IGP-M Linked rate & 0.000 & 0.00 & 0.005 & 0.48 & $(0.001)$ & 0.04 \\
\hline 126 & IGP-M Linked rate & 0.001 & 0.00 & 0.007 & 0.72 & 0.001 & -0.03 \\
\hline 252 & IGP-M Linked rate & 0.001 & 0.00 & 0.008 & 1.04 & 0.006 & -0.30 \\
\hline 378 & IGP-M Linked rate & 0.002 & 0.00 & 0.006 & 0.66 & 0.009 & -0.53 \\
\hline 504 & IGP-M Linked rate & 0.004 & 0.00 & 0.003 & 0.46 & 0.013 & -0.27 \\
\hline 630 & IGP-M Linked rate & 0.005 & 0.00 & 0.001 & 0.08 & 0.018 & -0.21 \\
\hline 756 & IGP-M Linked rate & 0.007 & 0.00 & $(0.002)$ & -0.24 & 0.024 & 0.32 \\
\hline 1008 & IGP-M Linked rate & 0.010 & 0.00 & $(0.009)$ & -0.74 & 0.036 & 1.75 \\
\hline 1260 & IGP-M Linked rate & 0.013 & 0.00 & $(0.016)$ & -2.78 & 0.048 & 6.32 \\
\hline 2520 & IGP-M Linked rate & 0.022 & 0.00 & $(0.052)$ & 0.57 & 0.102 & 14.96 \\
\hline 3780 & IGP-M Linked rate & 0.030 & 0.00 & $(0.089)$ & -12.69 & 0.153 & 18.41 \\
\hline 5040 & IGP-M Linked rate & 0.041 & 0.00 & $(0.139)$ & 13.18 & 0.220 & 16.63 \\
\hline 6300 & IGP-M Linked rate & 0.055 & 0.00 & $(0.203)$ & 15.18 & 0.302 & -0.10 \\
\hline 7560 & IGP-M Linked rate & 0.070 & 0.00 & $(0.274)$ & 10.31 & 0.392 & -0.55 \\
\hline 8820 & IGP-M Linked rate & 0.085 & 0.00 & $(0.348)$ & 6.15 & 0.484 & -0.62 \\
\hline
\end{tabular}


Table 7 Cont

\begin{tabular}{|c|c|c|c|c|c|c|c|}
\hline & & SSC & & INS & & PF & \\
\hline Maturity & Risk factor & Marginal & Component (\%) & Marginal & Component (\%) & Marginal & Component (\%) \\
\hline 10080 & IGP-M Linked rate & 0.101 & 0.00 & $(0.423)$ & 3.53 & 0.576 & -0.54 \\
\hline 11340 & IGP-M Linked rate & 0.116 & 0.00 & $(0.498)$ & 1.91 & 0.668 & -0.40 \\
\hline 12600 & IGP-M Linked rate & 0.131 & 0.00 & $(0.574)$ & 1.49 & 0.760 & -0.65 \\
\hline 1 & IPCA & 0.002 & 1.28 & 0.003 & 5.78 & $(0.001)$ & 0.13 \\
\hline 63 & IPCA Linked rate & 0.001 & 0.02 & 0.003 & 0.66 & 0.002 & 0.00 \\
\hline 126 & IPCA Linked rate & 0.001 & 0.02 & 0.007 & 2.16 & 0.003 & 0.01 \\
\hline 252 & IPCA Linked rate & 0.003 & 0.13 & 0.007 & 2.71 & 0.007 & 0.04 \\
\hline 378 & IPCA Linked rate & 0.007 & 0.44 & 0.006 & 2.11 & 0.014 & 0.07 \\
\hline 504 & IPCA Linked rate & 0.010 & 0.36 & 0.003 & 0.80 & 0.022 & 0.14 \\
\hline 630 & IPCA Linked rate & 0.013 & 0.28 & $(0.000)$ & -0.07 & 0.029 & 0.21 \\
\hline 756 & IPCA Linked rate & 0.015 & 0.76 & $(0.004)$ & -1.06 & 0.034 & 0.32 \\
\hline 1008 & IPCA Linked rate & 0.018 & 1.15 & $(0.012)$ & -2.61 & 0.044 & 0.54 \\
\hline 1260 & IPCA Linked rate & 0.020 & 2.49 & $(0.019)$ & -3.09 & 0.053 & 1.57 \\
\hline 2520 & IPCA Linked rate & 0.032 & 3.48 & $(0.061)$ & 9.48 & 0.100 & 3.84 \\
\hline 3780 & IPCA Linked rate & 0.048 & 1.90 & $(0.107)$ & 22.18 & 0.158 & 4.71 \\
\hline 5040 & IPCA Linked rate & 0.066 & 1.98 & $(0.154)$ & 17.36 & 0.218 & 5.66 \\
\hline 6300 & IPCA Linked rate & 0.084 & 1.48 & $(0.198)$ & 9.44 & 0.278 & 5.57 \\
\hline 7560 & IPCA Linked rate & 0.103 & 2.32 & $(0.241)$ & 0.94 & 0.337 & 11.08 \\
\hline 8820 & IPCA Linked rate & 0.122 & 1.08 & $(0.282)$ & -12.76 & 0.396 & 8.93 \\
\hline 10080 & IPCA Linked rate & 0.142 & 0.17 & $(0.321)$ & 0.31 & 0.454 & 1.47 \\
\hline 11340 & IPCA Linked rate & 0.163 & 0.00 & $(0.359)$ & 0.59 & 0.511 & 0.00 \\
\hline 12600 & IPCA Linked rate & 0.183 & 0.00 & $(0.395)$ & 0.57 & 0.567 & 0.00 \\
\hline 1 & $\mathrm{RR}$ & $(0.094)$ & 78.53 & $(0.033)$ & 3.52 & 0.023 & 1.76 \\
\hline 63 & RR Linked rate & $(0.000)$ & -0.02 & $(0.000)$ & 0.00 & 0.001 & -0.01 \\
\hline 126 & RR Linked rate & $(0.000)$ & -0.03 & $(0.000)$ & 0.00 & 0.002 & -0.03 \\
\hline 252 & RR Linked rate & $(0.000)$ & 0.00 & $(0.001)$ & 0.01 & 0.004 & -0.08 \\
\hline 378 & RR Linked rate & $(0.000)$ & 0.06 & $(0.002)$ & 0.01 & 0.007 & -0.08 \\
\hline 504 & RR Linked rate & $(0.000)$ & 0.07 & $(0.004)$ & 0.02 & 0.010 & -0.05 \\
\hline 630 & RR Linked rate & $(0.001)$ & 0.07 & $(0.006)$ & 0.03 & 0.014 & -0.03 \\
\hline 756 & RR Linked rate & $(0.001)$ & 0.13 & $(0.009)$ & 0.05 & 0.018 & -0.02 \\
\hline 1008 & RR Linked rate & $(0.001)$ & 0.25 & $(0.015)$ & 0.12 & 0.025 & -0.02 \\
\hline 1260 & RR Linked rate & $(0.002)$ & 0.41 & $(0.021)$ & 0.44 & 0.033 & -0.03 \\
\hline 2520 & RR Linked rate & $(0.002)$ & 0.09 & $(0.048)$ & 1.03 & 0.067 & -0.10 \\
\hline 3780 & RR Linked rate & $(0.001)$ & 0.00 & $(0.071)$ & 0.81 & 0.102 & -0.10 \\
\hline 5040 & RR Linked rate & 0.000 & 0.00 & $(0.094)$ & 0.53 & 0.139 & -0.08 \\
\hline 6300 & RR Linked rate & 0.002 & 0.00 & $(0.118)$ & 0.30 & 0.177 & -0.06 \\
\hline 7560 & RR Linked rate & 0.004 & 0.00 & $(0.143)$ & 0.17 & 0.216 & -0.03 \\
\hline 8820 & RR Linked rate & 0.006 & 0.00 & $(0.168)$ & 0.09 & 0.255 & -0.02 \\
\hline 10080 & RR Linked rate & 0.008 & 0.00 & $(0.193)$ & 0.04 & 0.293 & -0.01 \\
\hline 11340 & RR Linked rate & 0.010 & 0.00 & $(0.219)$ & 0.02 & 0.331 & 0.00 \\
\hline 12600 & RR Linked rate & 0.012 & 0.00 & $(0.244)$ & 0.01 & 0.368 & 0.00 \\
\hline 21 & Fixed rate & $(0.000)$ & 0.00 & $(0.000)$ & 0.01 & 0.000 & 0.00 \\
\hline 63 & Fixed rate & 0.000 & 0.00 & $(0.000)$ & 0.04 & 0.001 & 0.00 \\
\hline 126 & Fixed rate & 0.001 & 0.00 & $(0.000)$ & 0.06 & 0.003 & 0.00 \\
\hline 252 & Fixed rate & 0.002 & 0.02 & $(0.002)$ & 0.12 & 0.008 & 0.06 \\
\hline 378 & Fixed rate & 0.005 & 0.30 & $(0.005)$ & -0.25 & 0.015 & 0.01 \\
\hline 504 & Fixed rate & 0.007 & 0.37 & $(0.010)$ & -0.06 & 0.022 & 0.09 \\
\hline 630 & Fixed rate & 0.008 & 0.04 & $(0.016)$ & 0.53 & 0.030 & 0.01 \\
\hline 756 & Fixed rate & 0.010 & 0.08 & $(0.023)$ & -0.15 & 0.039 & 0.37 \\
\hline 1008 & Fixed rate & 0.012 & 0.00 & $(0.036)$ & 0.27 & 0.055 & 0.09 \\
\hline 1260 & Fixed rate & 0.014 & 0.20 & $(0.049)$ & -0.75 & 0.071 & 0.12 \\
\hline 2520 & Fixed rate & 0.025 & 0.06 & $(0.105)$ & -0.23 & 0.142 & 0.39 \\
\hline 3780 & Fixed rate & 0.036 & 0.00 & $(0.157)$ & 0.00 & 0.214 & 0.00 \\
\hline 1 & Stock & 0.010 & 0.04 & $(0.066)$ & -2.52 & 0.108 & 0.00 \\
\hline 1 & Commodities & $(0.151)$ & 0.00 & $(0.097)$ & 0.00 & $(0.370)$ & 0.00 \\
\hline
\end{tabular}

SSC: special savings company; PF: pension fund; INS: insurer; IGP-M: Brazilian General Market Price Index; IPCA: Brazilian Consumer Price Index; RR: reference rate.

Source: Elaborated by the authors. 
With the change in the covariance matrix used, not only the capital requirement changes, but also the evaluation regarding which strategies to use to manage each entity's VaR.

For the SSC, the main factor contributing to the VaR is the $R R$, while in the calculation with the matrix up to July 2014 it was the IPCA maturities.

In the case of the INS, the greatest contribution to the VaR changes from the IPCA rate to the intermediate IPCA maturities, with the new matrix. As for the PF, the $\mathrm{VaR}$ results indicate the intermediate IGP-M maturities as the greatest contribution to VaR with both matrices.

Given the regulatory model adopted, Susep's concern is observed in relation to the risk of decay of risk factors and periods between assets and liabilities, given that the VaR calculation is applied to net exposures, which highlights the importance of ALM practices. Currently, market risk management in many of the supervised entities is geared towards evaluating and monitoring the variation in the value of financial investments in isolation, without observing the behavior of the respective liabilities.
Therefore, conservative practices for market risk adopting the restricted perspective of financial assets (for example, concentrating portfolio investments into low volatility government bonds, such as Financial Treasury Bills) may not be the ones that result in the lowest capital allocation, which represents a new challenge for the risk managers of these companies.

It is worth mentioning, however, that the investment aims of the regulated entities can go beyond simply reducing required capital. It is common to find, for example, investment strategies that aim, via allocation into assets indexed to the IPCA, to address liabilities indexed to the RR, seeking the potential financial gains to the detriment of the need for market risk capital. Moreover, ALM practices often consider the assumption of new business instead of a run-off company, despite this being a concept embedded into the regulatory model.

All of these challenges make the current need to use the ALM apparent in order to address the different aims encountered, whether these are required by the regulator, or are derived from market operations.

\section{CONCLUSIONS}

The introduction of market risk capital regulations for INSs, PFs, SSCs, and reinsurers leads to various challenges for the market, not only from a financial impact perspective, but also for aspects of management and regulation.

The results presented in the cases studied in this paper show that there is an impact for the entities and that this impact can lead to large variations, depending on the assumptions used.

The covariance matrix used for the purposes of calculating the regulatory capital for market risk was updated only up to July 2014 and did not capture the effect of the volatility of the current Brazilian market, which may be underestimating risk, as shown in this paper's result, given that this date precedes the electoral period and the loss of investment grade status, which are, for example, events that contributed to an increase in volatility.

The financial impact of the introduction of market risk capital tends to incentivize changes in management practices, especially in relation to the ALM, remembering that asset and liability management is a much broader concept that merely pairing assets and liabilities. There is a need to understand and define the aim of the ALM, such as: (i) to optimize regulatory capital, (ii) to optimize economic capital, and (iii) to optimize financial return, observing a capital budget etc. The establishment of an ALM practice was also included in the rule that addresses enterprise risk management (ERM), published in Susep
Circular Letter n. 517 (Susep, 2015), and altered by Susep Circular Letter n. 521 (Susep, 2015).

The rule for market risk capital also tends to influence the way companies engage in market risk management, which usually only emphasizes financial assets, coming to incorporate a more holistic view of risk and simultaneously analyzing assets and liabilities. This should even influence the organizational structures of companies, requiring more interaction between investment and actuarial areas.

Therefore, given the relevance of the topic that is the object of this research and its consequences, the need for more research into this is observed.

For future studies, we suggest developing other conceptual studies, such as:

- The solvency time horizon is different for each type of risk; therefore, what is the concept of the aggregated view for regulatory capital?

- Is there interest rate risk overlapping between the market risk capital model and the subscription risk one for PFs?

- When will the internal model be regulated?

Moreover, we recommend that future studies explore another topic that relates to this research, regarding the measurement of liabilities broken down into "current estimates" and "margin over the current estimates" (MOCE). 


\section{REFERENCES}

Alexander, C. (2009). Market risk analysis, value at risk models (Vol. 4). Hoboken: John Wiley \& Sons.

Basel Committee on Banking Supervision. (2004). International convergence of capital measurement and capital standards: a revised framework. Basel: BCBS.

Blake, D., Cairns, A. J., \& Dowd, K. (2001). Pension metrics: stochastic pension plan design and valueat-risk during the accumulation phase. Insurance: Mathematics and Economics, 29(2), 187-215.

Cairns, A. J., Blake, D., \& Dowd, K. (2006). Stochastic life styling: optimal dynamic asset allocation for defined contribution pension plans. Journal of Economic Dynamics and Control, 30(5), 843-877.

Carcano, N., \& Dall'O H. (2011). Alternative models for hedging yield curve risk: an empirical comparison. Journal of Banking \& Finance, 35(11), 2991-3000.

Directive of the European Parliament and of the Council. 2009. Directive 2009/138/EC of the European Parliament and of the Council of 25 November 2009. Solvency II.

Gourieroux, C., Laurent, J. P., \& Scaillet, O. (2000). Sensitivity analysis of values at risk. Journal of Empirical Finance, 7(3), 225-245.

International Association of Insurance Supervisors (2005). Insurance core principles. Basel: IAIS.

Morgan, J. P. (1996). Risk Metrics Technical Document. Morgan Guarantee Trust Company.

Nawalkha, S. K., Soto, G. M., \& Zhang, J. (2003). Generalized M-vector models for hedging interest rate risk. Journal of Banking \& Finance, 27(8), 1581-1604.

Ryan, R. J. (2014). The evolution of Asset/Liability Management (a summary). New York: CFA Institute.

Superintendence of Private Insurance. Susep Circular Letter n. 517, July $30^{\text {th }} 2015$. Retrieved from http://
www2.susep.gov.br/bibliotecaweb/docOriginal. aspx ?tipo $=1 \&$ codigo $=35656$

Superintendence of Private Insurance. Susep Circular Letter n. 521, November $24^{\text {th }} 2015$. Retrieved from http://www2.susep.gov.br/bibliotecaweb/ docOriginal.aspx?tipo $=1 \&$ codigo $=37077$

Superintendence of Private Insurance. (2015). Relatório Final do GT de Risco de Mercado. Retrieved from http://www.susep.gov.br/ setoressusep/cgsoa/coris/dicem/grupo-tecnico-derisco-de-mercado

Superintendence of Private Insurance. CNSP Resolution $n$. 158, 2006. Retrieved from http:// www.susep.gov.br/setores-susep/cgsoa/coris/ requerimentos-de-capital/arquivos/resol158-1.pdf

Superintendence of Private Insurance. CNSP Resolution $n .188,2008$. Retrieved from http:// www.susep.gov.br/setores-susep/cgsoa/coris/ requerimentos-de-capital/arquivos/resol188.pdf

Superintendence of Private Insurance. CNSP Resolution n. 228, 2010. Retrieved from http:// www2.susep.gov.br/bibliotecaweb/docOriginal. aspx?tipo $=1 \&$ codigo $=27426$

Superintendence of Private Insurance. CNSP Resolution n. 283, 2013. Retrieved from http:// www2.susep.gov.br/bibliotecaweb/docOriginal. aspx?tipo $=1 \&$ codigo $=30628$

Superintendence of Private Insurance. CNSP Resolution $n .317,2014$. Retrieved from http:// www2.susep.gov.br/bibliotecaweb/docOriginal. asp $\dot{x}$ ?tipo $=1$ \& codigo $=34205$

Superintendence of Private Insurance. CNSP Resolution n. 321, 2015. Retrieved from http:// www2.susep.gov.br/bibliotecaweb/docOriginal. aspx?tipo $=1 \&$ codigo $=35542$

Superintendence of Private Insurance. CNSP Resolution $n .343,2016$. Retrieved from http:// www2.susep.gov.br/bibliotecaweb/docOriginal. asp ? tipo $=1 \&$ codigo $=39648$

\section{Correspondence address}

\section{Betty Lilian Chan}

Fundação Escola de Comércio Álvares Penteado, Departamento de Ciências Contábeis

Avenida da Liberdade, 532, $8^{\circ}$ andar, Bloco E - CEP: 01502-001

Liberdade - São Paulo - SP - Brasil

Email: betty.chan@fecap.brv 